\title{
Oncologist Hepatobiliary
}

\section{Current Management of Gallbladder Carcinoma}

\author{
Andrew X. Zhu, ${ }^{a}$ Theodore S. Hong, ${ }^{a}$ Aram F. Hezel, ${ }^{b}$ David A. Kooby ${ }^{c}$ \\ ${ }^{a}$ Massachusetts General Hospital Cancer Center, Harvard Medical School, Boston, Massachusetts, USA; \\ bJames P. Wilmot Cancer Center, University of Rochester School of Medicine, Rochester, New York, USA; \\ ${ }^{\mathrm{c}}$ Winship Cancer Institute, Emory University School of Medicine, Atlanta, Georgia, USA
}

Disclosures: Andrew X. Zhu: Consultant/advisory role: Bayer, Genentech, Sanofi-Aventis; Theodore S. Hong: Consultant/advisory role: Bristol-Myers Squibb; Aram F. Hezel: None; David A. Kooby: None.

The content of this article has been reviewed by independent peer reviewers to ensure that it is balanced, objective, and free from commercial bias. No financial relationships relevant to the content of this article have been disclosed by the independent peer reviewers.

\begin{abstract}
Gallbladder cancer (GBC) represents the most common and aggressive type among the biliary tree cancers (BTCs). Complete surgical resection offers the only chance for cure; however, only $10 \%$ of patients with GBC present with early-stage disease and are considered surgical candidates. Among those patients who do undergo "curative" resection, recurrence rates are high. There are no established adjuvant treatments in this setting. Patients with unresectable or metastatic
\end{abstract}

GBC have a poor prognosis. There has been a paucity of randomized phase III data in this field. A recent report demonstrated longer overall survival with gemcitabine in combination with cisplatin than with gemcitabine alone in patients with advanced or metastatic BTCs. Molecularly targeted agents are under development. In this review, we attempt to discuss the current status and key issues involved in the management of GBC. The Oncologist 2010;15:168-181

\section{INTRODUCTION}

Biliary tract cancers (BTCs) are invasive adenocarcinomas that arise from the epithelial lining of the gallbladder and intrahepatic and extrahepatic (hilar and distal common bile duct) bile ducts. Although anatomically these malignancies are related and have similar metastatic patterns, each has a distinct clinical presentation, molecular pathology, and prognosis. Gallbladder cancer (GBC) is the most common cancer of the biliary tract and has a particularly high incidence in Chile, Japan, and northern India. The incidence of GBC steadily increases with age, women are affected two to six times more often than men, and GBC is more common in whites than in blacks. For GBC, several conditions associated with chronic inflammation are considered risk factors, which include gallstone disease, porcelain gallbladder, gallbladder polyps, chronic Salmonella infection, congenital biliary cysts, and abnormal pancreaticobiliary duct junction.

GBC is characterized by local invasion, extensive regional lymph node metastasis, vascular encasement, and distant metastases. In general, GBC is the most aggressive of the biliary cancers with the shortest median survival duration. Complete surgical resection offers the only chance for cure; however, only $10 \%$ of patients present with earlystage disease and are considered surgical candidates. Among those patients who do undergo "curative" resection,

Correspondence: Andrew X. Zhu, M.D., Ph.D., Tucker Gosnell Center for Gastrointestinal Cancers, Massachusetts General Hospital Cancer Center, LH/POB 232, 55 Fruit Street, Boston, Massachusetts 02114, USA. Telephone: 617-643-3415; Fax: 617-724-3166; e-mail: azhu@partners.org Received November 30, 2009; accepted for publication January 18, 2010; first published online in The Oncologist Express on February 10, 2010. CAlphaMed Press 1083-7159/2010/\$30.00/0 doi: 10.1634/theoncologist.2009-0302 
recurrence rates are high. Patients with unresectable or metastatic GBC have a poor prognosis. There has been a paucity of randomized phase III data in this field, until a recent report demonstrating longer overall survival (OS) with gemcitabine in combination with cisplatin than with gemcitabine alone in patients with advanced or metastatic BTCs [1]. In this review, we attempt to discuss the current status and the key issues involved in the current management of GBC.

\section{Surgical Management}

Complete surgical resection remains the only potentially curative treatment for primary adenocarcinoma of the gallbladder. Several basic concepts of surgical management of this illness are straightforward, whereas others remain controversial. Given the relatively low incidence of this malignancy, there is a paucity of randomized data to address these controversial issues. Much of what governs clinical decision making is predicated on retrospective data and conventional wisdom.

\section{Management of the Primary Tumor}

Aggressive surgical therapy of GBC is becoming more common as large institutional series from the U.S. and abroad demonstrate longer survival times from more extensive resections [2-4] while morbidity and mortality continue to improve [5]. The American Joint Committee on Cancer (AJCC) T stage, patient fitness, and presence or absence of distant metastatic disease drive clinical decision making regarding whether a potentially curative resection can be offered. An unusual aspect of GBC management is that it is often diagnosed incidentally after routine cholecystectomy for what is believed to be benign disease preoperatively. Thus, approximately half the patients have undergone cholecystectomy prior to referral to a surgeon with expertise in hepatobiliary surgery $[3,6]$. Many of these cases require a second, definitive procedure, and $\mathrm{T}$ stage usually guides operative planning.

It is important to be familiar with the changes in the tumor-node-metastasis staging of GBC when comparing data from various studies over the past decade, because the staging groups have changed substantially from the Fifth, Sixth, and now most recent Seventh Edition of the AJCC Cancer Staging Manual [7]. For example, a node-negative T2 tumor (involving the perimuscular connective tissue or subserosa) represented stage II disease in the Fifth Edition, but was changed to stage Ib in the Sixth Edition, and is now stage II disease again in the Seventh Edition. This change bears relevance to discussion of surgical management, because $\mathrm{T} 1$ and $\mathrm{T} 2$ tumors are the primary targets of surgical therapy, yet precise management differs between the two. In creation of the Seventh Edition, major staging changes made in the Sixth Edition largely reverted back to what was seen in the Fifth Edition. As such, the remaining discussion will focus on $\mathrm{T}$ staging rather than overall staging groups.

\section{Tis and T1a GBC}

It is universally accepted that cholecystectomy alone is sufficient therapy for early tumors, confined to the mucosa (Tis) or lamina propria (T1a). One study compared 80 patients who underwent cholecystectomy alone with those who underwent "radical cholecystectomy" for clinically nonapparent GBC, which included both $\mathrm{T} 1$ and $\mathrm{T} 2$ disease [8]. Patients with T1 disease had a disease-specific survival rate after simple cholecystectomy of $100 \%$ at 5 years, arguing against any possible benefit of more aggressive surgical resection.

Unfortunately, few cases of GBC are identified at these early, curable stages. Recent large reviews of the National Cancer Database [9] and the Surveillance, Epidemiology, and End Results (SEER) registry [2] both reported that $<10 \%$ of cases fall in this category; thus, surgical management is often more involved.

\section{$T 1 b G B C$}

T1b tumors invade the muscular layer of the gallbladder. Some series support simple cholecystectomy as sufficient management [10], whereas others call for radical resection in these cases [11-13]. Data are scant, because these lesions are uncommon. One study supporting radical resection for $\mathrm{T} 1 \mathrm{~b}$ tumors identified a significantly high proportion of cases with residual cancer in the resected liver bed. In one multicenter evaluation of 115 cases of reresection after prior cholecystectomy [14], $46 \%$ of patients had residual disease in the reresection specimen on final histologic analysis. Current recommendations from the National Comprehensive Cancer Network support simple cholecystectomy for $\mathrm{T} 1 \mathrm{a}$ lesions and radical cholecystectomy for $\mathrm{T} 1 \mathrm{~b}$ lesions [15].

\section{T2 GBC}

T2 tumors, which invade the perimuscular connective tissue, are best managed with en bloc resection of the liver bed (Couinaud segments 4B and 5). It is generally accepted that radical en bloc resection of $\mathrm{T} 2$ tumors offers greater benefit over conventional cholecystectomy alone in terms of greater long-term survival times. In an assessment of 98 patients with primary GBCs identified only after routine cholecystectomy, 48 patients had T2 disease. The 5-year survival rate was $40 \%$ after cholecystectomy alone, and it 
was $90 \%$ following more radical resection including the liver bed [16]. In a separate analysis of 28 patients, the survival rate was $59 \%$ at 5 years with radical resection of the gallbladder liver bed versus $17 \%$ with cholecystectomy alone [17]. Several other series provide similar findings [18-21]. In the absence of randomized data, we presently advocate that all patients with T2 GBCs who are fit and properly staged to exclude distant metastases be offered radical cholecystectomy, or reresection of the liver bed after an incidental finding of GBC following cholecystectomy.

\section{T3 and T4 GBC}

T3 tumors perforate the serosa and/or directly invade adjacent organs such as the liver, duodenum or stomach, colon, pancreas, omentum, or extrahepatic bile ducts. As such, they are usually amenable to radical resection; however, the morbidity from these operations may be substantial. T4 tumors are those that invade the main portal vein or hepatic artery, and those that invade two or more extrahepatic organs or structures. T4 tumors are usually not amenable to surgical resection, or carry substantial morbidity and mortality when approached surgically [22].

Several series have focused on outcomes in patients with these locally advanced tumors and arrive at different conclusions. A review of 724 cases of GBC by the French Surgical Association in 1994 suggested a poor prognosis for these patients [23]. In that multicenter analysis, $85 \%$ of cases were identified as $\mathrm{T} 3$ or $\mathrm{T} 4$, and this group as a whole carried an OS time of 2-8 months. The conclusion drawn from that report was that little progress had been made in the therapy of GBC over the previous decade. On the other hand, a series from Japan published 1 year later purported the benefits of extended resection in patients with stage III disease, citing a 5 -year survival rate of $44 \%$ in these patients [24]. Other series have corroborated this assertion [25-27]. Improvements in surgical therapy, anesthetic management, and intensive care have diminished the mortality and morbidity of radical hepatobiliary surgery. Provided that the patient is fit and properly staged, en bloc resection may be indicated for many $\mathrm{T} 3$ and some $\mathrm{T} 4$ GBCs.

\section{Additional Surgical Considerations}

\section{Diagnostic Laparoscopy}

Diagnostic laparoscopy at the time of exploration may allow the surgeon to identify radiologically inapparent peritoneal metastases without committing the patient to formal laparotomy incision. This maneuver can minimize patient trauma, which in turn may shorten hospital stay, conserve limited resources, and expedite transition to palliative treatment with chemotherapy.

A prospective evaluation of 100 consecutive patients with biliary cancers staged by laparoscopy at the time of operation identified unresectable or metastatic disease in $\sim 50 \%$ of patients [28]. Other authors have suggested that routine staging laparoscopy may represent an inappropriate use of resources [29]; however, the finding that about one third of GBC patients being explored may have peritoneal or hepatic metastases not evident on computed tomography (CT) or magnetic resonance imaging (MRI) points toward its utility in sparing patients unneeded operations [30]. Our current recommendation is to add routine diagnostic laparoscopy to all GBC-directed operations.

\section{Lymph Node Dissection}

As with many other malignancies, lymphadenectomy is advocated in GBC as a staging procedure [18, 31, 32]. Formal portal lymphadenectomy, to include the nodal tissue of the hepatoduodenal ligament and portacaval and retroduodenal regions, is strongly recommended, primarily based on data from Japan [31,33]. Whether or not node dissection contributes to longer survival cannot be proven from existing data; however, in the absence of distant metastases, nodal status provides the most valuable prognostic information for patients with operable GBC. Therefore, we recommend routine lymphadenectomy. An exception to this recommendation is if a T1a cancer was removed incidentally. In that case, the data do not support re-exploring the patient for lymphadenectomy because cholecystectomy alone is sufficient surgical therapy [8].

\section{Bile Duct Resection}

If the gallbladder was removed in a prior setting, there are several important considerations. Assuming a second operation is indicated, the surgeon performing the definitive oncologic procedure will want to know the status of the cystic duct margin from the cholecystectomy specimen. If it was negative for malignant cells, then many surgeons spare the biliary tree and perform a lymphadenectomy in conjunction with a 4B and 5 gallbladder bed liver resection. If the cystic duct margin was positive, then the surgeon may try to identify the cystic duct intraoperatively. If this maneuver is successful, then the cystic duct can usually be resampled. If positive, or if the cystic duct stump is not identified, then the common duct is usually resected with the portal nodes and liver bed to optimize surgical margins, and a roux-en-y hepaticojejunostomy is fashioned. Of note, cystic duct involvement is associated with a poorer prognosis [34].

Removing the bile duct may also improve node clearance, and some surgeons prefer to do this routinely. A re- 
Table 1. Surgical management of gallbladder carcinoma

\begin{tabular}{|c|c|}
\hline Stage & Recommendation \\
\hline Tis (confined to mucosa) or T1a (lamina propria) & Simple cholecystectomy \\
\hline T1b (invading the muscular layer) & $\begin{array}{l}\text { Radical cholecystectomy is recommended, although some } \\
\text { series support simple cholecystectomy }\end{array}$ \\
\hline $\mathrm{T} 2$ tumors (invading the perimuscular connective tissue) & Radical en bloc resection including liver bed \\
\hline $\begin{array}{l}\text { T3 tumors (those that perforate the serosa and/or directly } \\
\text { invade the liver and/or one other adjacent organ) }\end{array}$ & Radical resection selectively \\
\hline $\begin{array}{l}\text { T4 tumors (those that invade the main portal vein or hepatic } \\
\text { artery, and/or those that invade two or more extrahepatic } \\
\text { organs or structures) }\end{array}$ & Generally unresectable \\
\hline
\end{tabular}

cent report examined the survival benefits associated with elective bile duct resection, and noted no benefit to this approach [4]. We are not in favor of routine radical bile duct resection, and feel that it should be used to obtain a negative margin when the cystic duct stump is positive.

\section{Port Site Resection}

If the gallbladder was removed laparoscopically, the surgeon will want to know if the organ was torn or ruptured and if a protective bag was used to prevent mechanical seeding of the wound at the time of specimen extraction. If the gallbladder was torn at the initial procedure, there may be a greater likelihood of peritoneal seeding, and if no bag was used, the wound through which it was removed may be at greater risk for harboring tumor cells. Most surgeons in this case resect the extraction site or all port sites, although the benefit of this maneuver is not supported by data in humans $[35,36]$. We feel that port site excision provides additional staging information that can help inform patients of recurrence risk, and is therefore beneficial but not absolutely necessary.

\section{Incidental Discovery of GBC at the Time of Noncurative Cholecystectomy}

Another question is whether patients who undergo definitive surgical resection in one setting have better outcomes than those who had their gallbladder removed in a prior setting and were found to have cancer incidentally on histologic analysis. Of 102 patients who underwent potentially curative resections, 80 had noncurative cholecystectomies as a first step [27]. Survival for these 80 patients was the same as for the 22 patients who had definitive resection in one setting. In another series of 107 patients, 39 patients were found to have GBC incidentally at the time of laparoscopic cholecystectomy [3]. Six were immediately converted for definite oncologic resection, and 33 had noncurative cholecystectomy and subsequent referral to an experienced surgeon. Both groups had a 33\% 5-year survival rate, so definitive reresection is further supported.

In summary (Table 1), successful surgical therapy of GBC requires a high level of suspicion for the diagnosis in patients with gallbladder wall thickening or polypoid lesions $>1 \mathrm{~cm}$ in diameter. Ideally, referral made to a surgeon with expertise in management of this disease occurs prior to cholecystectomy, so a definitive procedure obeying oncologic principles can be performed in one setting. In the event that the gallbladder is removed and cancer is incidentally identified, then consultation with a surgeon poised in the management of this disease should be obtained to ensure adequate surgical therapy is provided. At the time of cholecystectomy, surgeons should routinely report on gallbladder wall violation and whether or not the specimen is bagged prior to removal. If a cancer is identified incidentally in a cholecystectomy specimen, the pathologist should report on $\mathrm{T}$ stage, location of the tumor with respect to the liver bed or peritoneal surface, and histology of the cystic duct margin. This information, along with patient health assessment and staging CT or MRI, arms the surgeon performing the definitive procedure with the information he/ she needs to know.

\section{RADIATION THERAPY}

The role of adjuvant radiotherapy or chemoradiotherapy has been predicated on the observation that survival from advanced GBC, even in the setting of a radical resection, is poor. As with other upper abdominal gastrointestinal cancers, the role of adjuvant radiotherapy is based on an underlying assumption that (a) isolated locoregional failure represents a significant proportion of progression, (b) radiation or chemoradiation is effective at decreasing the risk for locoregional failure and hence survival, and (c) radiation therapy to this region is safe and tolerable. However, as a result of the relative rarity of this diagnosis, it is difficult 
to address the assumptions because the existing data are of mixed quality and conclusions.

\section{Patterns of Spread}

GBC has a high rate of regional metastasis. In one of the larger surgical series, surgical specimens from 48 patients who had radical/extended cholecystectomies for GBC were analyzed in 5-mm stepwise tissue sections [37]. Nodal spread was scored on a scale of zero to three ( 0 , no metastases; 1, cystic, paradochal, hilar; 2, peripancreatic head, portal, hepatic artery; 3, celiac, periduodenal, perimesenteric). In this group of 48 patients, eight (17\%) were found to have group 1 nodes, nine (18.8\%) were found to have group 2 nodes, and seven (14.5\%) were found to have more distant group 3 nodes. Only three of the 16 patients with group 2 or 3 nodes were able to undergo curative resection. Studies such as these suggest a possible niche for regional radiation therapy, in which these more distant nodal groups are commonly encompassed for pancreatic cancer and cholangiocarcinoma (CC).

However, although GBC appears to have a significant regional pattern of spread, there is some suggestion that there may be a greater risk for synchronous distant metastatic spread than in CC. In a large study from Memorial Sloan-Kettering Cancer Center, 97 patients with GBC and 76 patients with hilar $\mathrm{CC}$ who underwent potentially curative resection were evaluated for patterns of initial disease recurrence [38]. In comparison with hilar CC, patients with GBC had a significantly shorter time to recurrence (11.5 months for GBC, versus 20.3 months; $p=.007$ ). Furthermore, patients with GBC were far more likely to have a distant site involved at the initial time of recurrence $(85 \%$ for $\mathrm{GBC}$, versus $41 \% ; p<.001$ ). The authors of that study concluded that GBC patients were even less likely to benefit from locoregional therapy given the high rate of synchronous distant disease. These types of conflicting data have made routine recommendations for chemoradiation problematic.

\section{Adjuvant Radiation or Chemoradiation}

The data regarding the role of adjuvant radiation therapy are even more sparse and generally limited to very small retrospective series and anecdotal reports. These series are often a mix of extrahepatic CCs and GBCs, which can be problematic, as the Memorial Sloan-Kettering Cancer Center patterns of failure data suggest. Furthermore, these series often combined patients with curative surgery with those with palliative surgery.

Early reports evaluating radiation therapy primarily demonstrated that radiation therapy could be safely given and may have some efficacy. One representative study re- ported by Houry and colleagues evaluated 20 patients with GBC who were treated postoperatively in 1977-1987 [39]. Curative resection was performed in four patients, partial resection was performed in 12 patients, and no resection was done in the remaining four patients. Patients received $3,200-5,500$ rads (mean, 4,200 rads), which is similar to 32-55 Gy. In that study, no adverse effects or complications were noted from treatment. Two of the four patients who had curative resections were long-term survivors. In another similar study, Mahe and colleagues reported the outcomes of 19 patients who underwent postoperative radiotherapy for GBC in 1980-1988 [40]. Eleven patients had complete resections, six had grossly incomplete resections, and two had palliative drainage. In the completely resected patients, the OS rate was $36 \%$ at 60 months. All eight patients who had palliative surgery died from cancer after 4-20 months.

Because most institutions have a preference regarding adjuvant therapy, there are very few studies that have been able to evaluate whether radiation improves survival. Some studies have suggested a benefit to radiation therapy [3944], whereas others have not [45]. Two relatively small, modern series highlight the limitations of the existing data. In a negative study by Itoh and colleagues, 18 patients who had GBC were evaluated [45]. Eleven patients had an R0 resection, five had an R1 resection, and two had an R2 resection. Five patients received radiation therapy postoperatively and 13 did not. The 5-year OS rate was $21 \%$ in the radiation group and $50 \%$ without radiation $(p=.33)$. In contrast, a study by Lindell and colleagues evaluated the role of combined external beam radiation therapy and intraoperative radiation therapy in 20 patients who underwent an extended operation [42]. After 10 patients had been managed with surgery alone, the institution underwent a change in treatment paradigm, whereby the next 10 patients received radiation therapy. Radiation therapy appeared to be associated with a higher 5-year actuarial survival rate of $47 \%$, versus $13 \%$ with surgery alone (not significant). It is important to note that, in both these series, the absolute difference at 5 years appeared quite large but was not statistically significant as a result of the small numbers. These representative series highlight the paucity of quality data regarding the role of adjuvant radiation therapy for GBC.

To address the problem of small numbers in retrospective GBC studies, Mojica and colleagues performed a SEER study to evaluate the role of radiation therapy in GBC [43]. They identified 3,187 cases of GBC for 1992-2002 from the SEER database. Surgical intervention was a component of therapy in 2,325 (73\%) cases. Simple cholecystectomy was performed in $77 \%$ of cases. Patients with unknown surgery or distant metastases were excluded, 
leaving 1,799 evaluable patients. Of those patients, $31 \%$ were stage I, $60 \%$ were stage II, and $8 \%$ were stage III. Twenty percent of the patients received radiation therapy. The group receiving radiation and the group treated with surgery alone were well balanced with regard to surgery type, tumor grade, and tumor size. The radiation group was somewhat younger (68 years versus 74 years; $p<.0001$ ). However, the radiation group had more advanced patients, with fewer stage I patients ( $31 \%$ versus $49 \%$; $p<.0001)$. The group of patients who received radiation therapy had a significantly longer median survival time than the group who did not (14 months versus 8 months; $p<.0001$ ). A subgroup analysis demonstrated that patients with positive nodes had the greatest benefit from radiation, with a longer median survival time of 16 months, versus 5 months $(p<$ .0001 ). This benefit persisted even in the setting of a radical surgery, with a median survival time of 13 months, versus 6 months $(p=.017)$. Patients with liver invasion but negative lymph nodes (T3 N0) also benefited from radiation therapy, with a median survival time of 14 months, versus 11 months $(p=.01)$. Patients with stage I disease did not appear to benefit from radiation therapy.

Because of the use of concurrent 5-fluorouracil (5-FU)based chemotherapy for most gastrointestinal cancers, some more contemporary series have evaluated the use of chemoradiation in the setting of GBC [46]. In a relatively small series from the Mayo Clinic, 21 consecutive patients in 1985-1987 were treated with radiation (median dose, 54 Gy) and concurrent 5-FU. Radiation fields encompassed the tumor bed and draining lymphatics. Twelve patients had no residual disease after surgery, five had microscopic disease, and four had gross residual disease. The 5-year OS rate for the whole cohort was $33 \%$. In the patients with no microscopic disease, the 5-year OS rate was $64 \%$, versus $0 \%$ in patients with residual disease. The authors contended that the $64 \%$ survival rate in the R0 group compared favorably with historical controls who did not receive postoperative therapy and recommended the use of postoperative chemoradiation.

In a more recent series published by Czito and colleagues, 22 patients at Duke with nonmetastatic GBC were treated with chemoradiation [47]. Whereas 20 of 22 patients first had a simple cholecystectomy, 11 patients subsequently underwent a radical reresection. Generally, patients were then treated with 45 Gy to the tumor bed and regional lymphatics followed by a boost of 5.4-10.8 Gy. Eighteen patients received concurrent 5-FU chemotherapy. The 5-year OS rate was 37\%. No single factor was found to significantly predict survival, including nodal status and margins. However, the strongest trend was seen in terms of the benefit of a radical procedure versus simple cholecystectomy (5-year OS rate, $51 \%$ versus $15 \% ; p=.10$ ).

Taken as a whole, it is clear that clinical data for radiation therapy suffer from heterogeneous clinical characteristics. However, one point that these studies demonstrate is that the use of adjuvant therapy cannot compensate for inadequate surgery. Obtaining an R0 resection with radical surgery appears to be associated with the best survival. Radiation therapy should be viewed as a means to improve upon optimal surgical management, rather than making up for inadequate surgery.

\section{Improving Safety of Radiation Therapy: Technical Considerations}

The primary goal of adjuvant radiation therapy is to optimize locoregional control. This necessitates treating the tumor bed and the porta hepatic and pancreaticoduodenal nodes, as well as consideration of the celiac nodes and retroperitoneal nodes. Historically, it has been difficult to safely treat these volumes given the large amount of liver and kidney that would need to be treated in these fields.

Newer technical advances have afforded the potential to create highly conformal radiation distributions and achieve greater normal tissue sparing. Intensity-modulated radiation therapy (IMRT) is the most commonly used highly conformal technique. In conventional radiation therapy, the physician defines the targets and at-risk organs on a CT scan. Beam angles are chosen and beams are shaped to cover the target with as much normal organ sparing as possible. This process is known as forward planning. In contrast, in IMRT treatment planning, a physician again defines the target and at-risk structures. However, the physician then assigns planning goals to each structure. A computer program then initiates an iterative process to optimize a radiation plan to meet these constraints. This process is known as inverse planning.

One study by Fuller and colleagues evaluated the feasibility of IMRT with image guidance for target localization in 10 patients with GBC [48]. Using IMRT, plans were created that allowed broad coverage to $\sim 50$ Gy with an additional tumor bed boost of $\sim 14$ Gy. Using IMRT, the liver and kidneys were protected to dose constraints well below the accepted levels of safety. These 10 patients were treated successfully, with only one grade 3 toxicity. The median survival duration in that group was 16.7 months.

In summary, our practice is currently to recommend adjuvant chemoradiation to stage II and stage III patients, or patients with R1 resections. Typically, the tumor bed and draining lymphatics are treated to a dose of $50.4 \mathrm{~Gy}$ in 1.8 Gy per fraction with concurrent 5-FU. A boost can be con- 

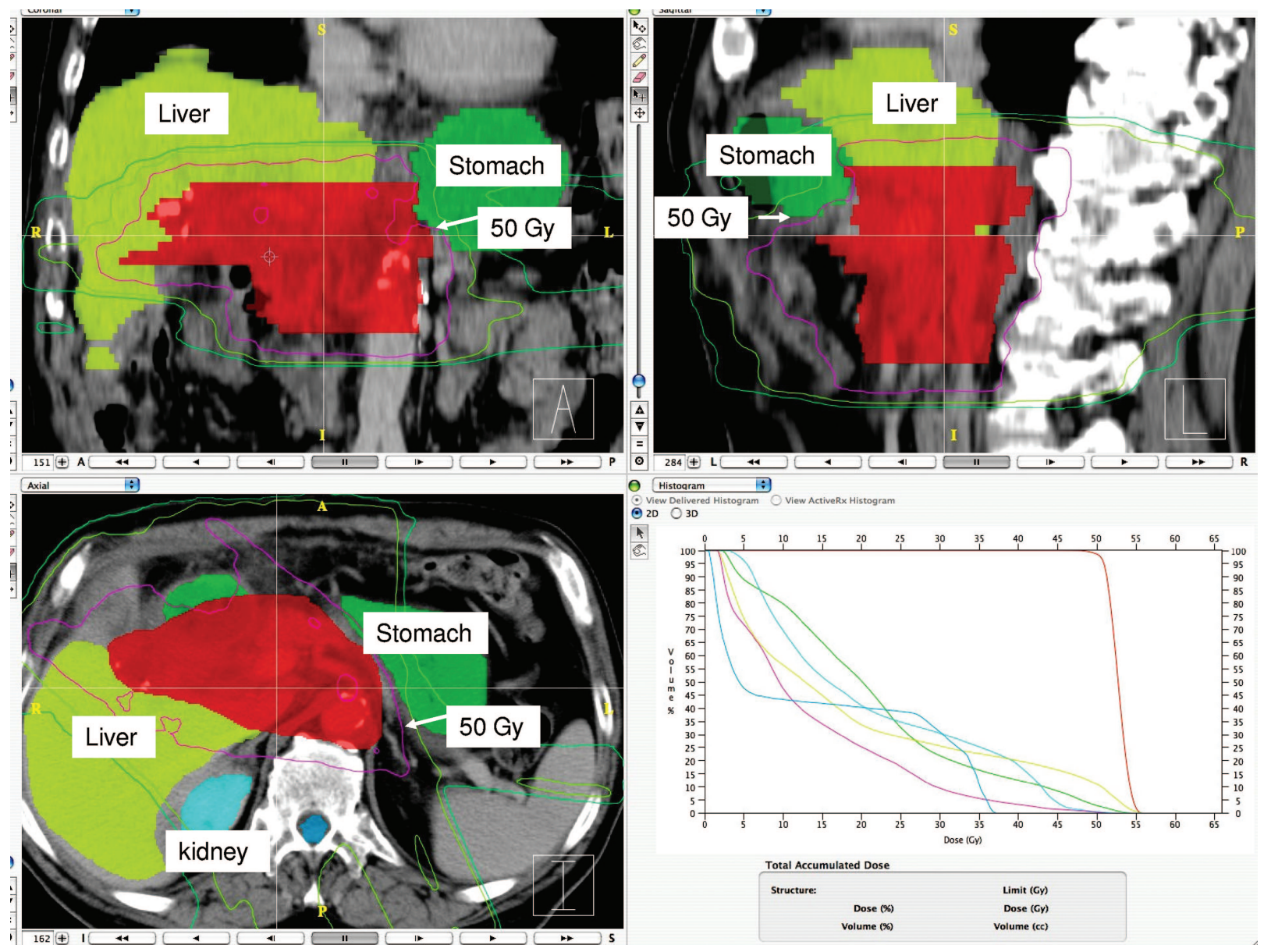

Figure 1. One patient with $\mathrm{T} 3$ gallbladder cancer after simple cholecystectomy followed by radical reresection who was treated with intensity-modulated radiotherapy.

sidered for patients with a positive margin if it can be confidently identified on a postoperative CT scan and a safe liver dose can be maintained. IMRT is considered if deemed necessary to maintain a safe normal tissue dose. Figure 1 shows a patient treated at Massachusetts General Hospital with IMRT for a T3 GBC after simple cholecystectomy followed by radical reresection.

\section{SYSTEMIC THERAPY}

Chemotherapy is used in several settings in the management of GBC: (a) adjuvant therapy following surgical resection, usually in combination with radiation; (b) for patients with locally advanced unresectable disease, given either alone or in combination with radiation; and (c) for patients with metastatic disease. Because of the rarity of bile duct cancer and GBC, most studies have grouped all BTC and GBC together, and there are very few GBC-specific studies. In addition, there is a paucity of randomized controlled studies in this disease.

\section{The Role of Chemotherapy in the Adjuvant and Locally Advanced Disease Settings}

The role of adjuvant chemotherapy in GBC has not been definitively evaluated in randomized trials. Most studies consist of small, heterogeneous groups of patients seen at a single institution. Several retrospective series and small phase II studies suggest superior outcomes for patients who receive postoperative chemoradiotherapy. The most common chemotherapeutic agent used is 5-FU, given concurrently with radiation. Likewise, 5-FU-based chemoradiation has been frequently used in locally advanced disease. However, the relative contribution of chemotherapy in addition to radiation has not been definitely defined.

\section{Chemotherapy for Advanced Disease}

As a result of the small number of patients and a heterogeneous patient population in BTC, as compared with other more common malignancies, randomized phase III studies have been a challenge to conduct. Most of the clinical ex- 
Table 2. Phase II studies with only gallbladder carcinoma patients

\begin{tabular}{lllll}
\hline Chemotherapy & $\begin{array}{l}\boldsymbol{n} \text { of } \\
\text { patients }\end{array}$ & $\begin{array}{l}\text { RR } \\
(\%)\end{array}$ & $\begin{array}{l}\text { Median } \\
\text { OS }\end{array}$ & Reference \\
\hline $\begin{array}{l}\text { Gemcitabine } \\
\text { Gemcitabine }+\end{array}$ & 42 & 36 & $30 \mathrm{wks}$ & {$[53]$} \\
$\begin{array}{l}\text { cisplatin } \\
\begin{array}{l}\text { Gemcitabine }+ \\
\text { cisplatin }\end{array}\end{array}$ & 30 & 36 & $7 \mathrm{mos}$ & {$[54]$} \\
\hline
\end{tabular}

Abbreviations: OS, overall survival; RR, response rate.

perience and data are derived from smaller phase II trials; it is largely from these trials that clinical standards are adopted by the gastrointestinal oncology community. There are very few studies that enroll only GBC patients. Therefore, experience with chemotherapy for GBC is generally based on studies for all patients with BTC. We recently reviewed the development of systemic therapy in advanced BTC [49].

\section{Responsiveness to Chemotherapy: GBC Versus Other BTCS}

A pooled analysis of 104 chemotherapy trials involving 1,368 BTC patients conducted in 1999-2006 suggested differences in clinical behavior and responsiveness to chemotherapy between GBC and other BTCs [50]. Among all patients, the median time to progression (TTP) and OS time were 4.1 months and 8.2 months, respectively. A subgroup analysis of GBC versus $\mathrm{CC}$, however, demonstrated a significantly higher response rate (RR), at 36\%, in GBC, versus $18 \%$ in CC, whereas the median OS time was longer for patients with CC, at 9.3 months, than for those with GBC, at 7.2 months. Importantly, that study demonstrated that gemcitabine and platinum-containing regimens led to consistently greater RRs and TTP than other therapies. The findings of that study are echoed in a retrospective analysis of BTC patients in Japan [51]. These results underscore the need to approach GBC as disease with a behavior distinct from other BTCs [52].

\section{Chemotherapy Trials in GBC}

Although most clinical trials in GBC have included all BTCs, there have been three trials exclusively enrolling GBC patients-one evaluating gemcitabine alone and two gemcitabine-cisplatin combination studies (Table 2). In one trial, 26 patients with metastatic or unresectable GBC and no prior chemotherapy received single-agent gemcitabine. Of the 25 evaluable patients, an overall RR of $36 \%$ (95\% confidence interval [CI], 17.1\%-57.9\%) and median survival time of 30 weeks were observed [53]. It should be emphasized that because of the single-arm nature of these small phase II studies, the survival values presented in Table 2 and Table 3 (see below) are observational in nature and not statistically valid.

Gemcitabine and cisplatin were evaluated in 44 patients. Among 42 evaluable patients there were four complete responses and 16 partial responses (PRs), for a RR of $48 \%$ (95\% CI, 32\%-71\%). The median survival time was 7 months (95\% CI, 6-8.5 months) and toxicity was reasonable [54]. A second experience with this combination demonstrated an overall RR of $36.6 \%$ and moderate hematologic toxicity [55]. These studies indicate that gemcitabine-based regimens have activity in GBC, which is also clear from studies among mixed populations of BTC patients. Below we summarize trials involving all BTCs.

\section{Fluoropyrimidine-Based Regimens}

5-FU and 5-FU-based regimens were among the first reported in GBC. Treatment with 5-FU and leucovorin led to a RR of $32 \%$ and an OS duration of 6 months [56]. Combination therapy with cisplatin consistently yields response rates of $10 \%-40 \%$ and median OS times somewhat better than those of 5-FU alone [57-60]. Studies of 5-FU in combination with the taxanes, etoposide, streptozotocin, methyl-CCNU, and irinotecan have not shown convincing superiority over 5-FU alone [61-63]. Similar to the experience with 5-FU and cisplatin combinations, phase II studies of capecitabine and cisplatin in BTC patients, including those with GBC, have similarly demonstrated somewhat higher RRs of $21 \%$ and $40 \%$ and median OS times of 9.1 months and 12.4 months, respectively [64, 65]. No grade 4 toxicities were reported. An earlier study evaluating epirubicin, cisplatin, and capecitabine exhibited an impressive RR of $40 \%$, but with an unremarkable median OS time of 8 months and significant incidences of grade 3 or 4 mucositis (19\%) and neutropenia (26\%) [66].

\section{Gemcitabine-Based Regimens}

Gemcitabine has been extensively evaluated in patients with metastatic BTCs $[67,68]$. RRs with single-agent gemcitabine have varied in the range of $0 \%-30 \%$, with median OS times in the range of 5-14 months [69-73]. Based on tolerability and promising RRs and OS times, more recent studies have focused on improving efficacy by combining gemcitabine with other agents (Table 3).

Gemcitabine and cisplatin or oxaliplatin combinations in BTC patients have been tested in at least eight published clinical trials to date, and have demonstrated RRs and median OS times somewhat better than those of the prior single-agent gemcitabine studies.

Four studies of gemcitabine plus cisplatin have been re- 
Table 3. Gemcitabine-based phase II studies in biliary tract cancers

\begin{tabular}{|c|c|c|c|c|}
\hline Chemotherapy & $n$ of patients & $\mathbf{R R}(\%)$ & $\begin{array}{l}\text { Median } \\
\text { OS (mos) }\end{array}$ & Reference \\
\hline \multicolumn{5}{|l|}{ Gemcitabine + capecitabine } \\
\hline $\begin{array}{l}\text { Gemcitabine, } 1,000 \mathrm{mg} / \mathrm{m}^{2} \text { days } 1 \text { and } 8 \text {; capecitabine, } 650 \mathrm{mg} / \mathrm{m}^{2} \\
\text { twice daily for } 14 \text { days, every } 21 \text { days }\end{array}$ & 45 & 31 & 14 & [82] \\
\hline $\begin{array}{l}\text { Gemcitabine, } 1,000 \mathrm{mg} / \mathrm{m}^{2} \text { on days } 1 \text { and } 8 \text {; capecitabine, } 650 \mathrm{mg} / \mathrm{m}^{2} \\
\text { twice daily for } 14 \text { days, every } 21 \text { days }\end{array}$ & 44 & 32 & 14 & [83] \\
\hline $\begin{array}{l}\text { Gemcitabine, } 1,000 \mathrm{mg} / \mathrm{m}^{2} \text { on days } 1 \text { and } 8 \text {; capecitabine, } 650 \mathrm{mg} / \mathrm{m}^{2} \\
\text { twice daily for } 14 \text { days, every } 21 \text { days }\end{array}$ & 75 & 29 & 12.7 & [84] \\
\hline $\begin{array}{l}\text { Gemcitabine, } 1,000 \mathrm{mg} / \mathrm{m}^{2} \text { on days } 1 \text { and } 8 \text {; capecitabine, } 650 \mathrm{mg} / \mathrm{m}^{2} \\
\text { twice daily for } 14 \text { days, every } 21 \text { days }\end{array}$ & 12 & 17 & 14 & [106] \\
\hline $\begin{array}{l}\text { Gemcitabine }+ \text { cisplatin } \\
\text { Gemcitabine, } 1,000 \mathrm{mg} / \mathrm{m}^{2} \text { on days } 1 \text { and } 8 \text {; cisplatin, } 30 \mathrm{mg} / \mathrm{m}^{2} \text { on } \\
\text { days } 1 \text { and } 8 \text {, every } 21 \text { days }\end{array}$ & 33 & 21 & 9.7 & [74] \\
\hline $\begin{array}{l}\text { Gemcitabine, } 1,000 \mathrm{mg} / \mathrm{m}^{2} \text { on days } 1 \text { and } 8 \text {; cisplatin, } 70 \mathrm{mg} / \mathrm{m}^{2} \text { on } \\
\text { day } 1 \text {, every } 21 \text { days }\end{array}$ & 24 & 21 & 9.3 & [76] \\
\hline $\begin{array}{l}\text { Gemcitabine, } 1,250 \mathrm{mg} / \mathrm{m}^{2} \text { on days } 1 \text { and } 8 \text {; cisplatin, } 60 \mathrm{mg} / \mathrm{m}^{2} \text { on } \\
\text { day } 1 \text {, every } 21 \text { days }\end{array}$ & 29 & 35 & 11 & [77] \\
\hline $\begin{array}{l}\text { Gemcitabine, } 1,250 \mathrm{mg} / \mathrm{m}^{2} \text { on days } 1 \text { and } 8 \text {; cisplatin, } 75 \mathrm{mg} / \mathrm{m}^{2} \text { on } \\
\text { day } 1 \text {, every } 21 \text { days }\end{array}$ & 40 & 26 & 8.4 & {$[75]$} \\
\hline \multicolumn{5}{|l|}{ Gemcitabine + oxaliplatin } \\
\hline $\begin{array}{l}\text { Gemcitabine, } 1,000 \mathrm{mg} / \mathrm{m}^{2} \text { on days } 1,8 \text {, and } 15 ; \text { oxaliplatin, } 100 \\
\mathrm{mg} / \mathrm{m}^{2} \text { on days } 1 \text { and } 15 \text {, every } 28 \text { days }\end{array}$ & 31 & 26 & 11 & [79] \\
\hline $\begin{array}{l}\text { Gemcitabine, } 1,000 \mathrm{mg} / \mathrm{m}^{2} \text { on days } 1 \text { and } 8 \text {; oxaliplatin, } 100 \mathrm{mg} / \mathrm{m}^{2} \\
\text { on day } 1 \text {, every } 2 \mathrm{wks}\end{array}$ & 24 & 50 & 14 & {$[80]$} \\
\hline $\begin{array}{l}\text { Gemcitabine, } 1,000 \mathrm{mg} / \mathrm{m}^{2} \text { on day } 1 \text {; oxaliplatin, } 100 \mathrm{mg} / \mathrm{m}^{2} \text { on day } 1 \text {, } \\
\text { every } 2 \text { wks; groups: A, good PS; group B, poor PS }\end{array}$ & $\begin{array}{l}33 \text { (group A) } \\
23 \text { (group B) }\end{array}$ & $\begin{array}{l}36 \\
22\end{array}$ & $\begin{array}{l}15.4 \\
7.6\end{array}$ & [78] \\
\hline
\end{tabular}

ported, with RRs of $21 \%-34.5 \%$ and median survival times of 9.3-11 months [74-77]. Gemcitabine-oxaliplatin combinations have been reported in three trials. The Groupe Cooperateur Multidisciplinaire en Oncologie study evaluated 56 patients with BTC treated with gemcitabine $(1,000 \mathrm{mg} /$ $\left.\mathrm{m}^{2}\right)$ and oxaliplatin $\left(100 \mathrm{mg} / \mathrm{m}^{2}\right)$ every 2 weeks and stratified patients based on Eastern Cooperative Oncology Group performance status (PS) score $(0-2$ versus $>2)$ and bilirubin $(<2.5 \mathrm{mg} / \mathrm{dl}$ versus $>2.5 \mathrm{mg} / \mathrm{dl})$ [78]. The median OS time among good PS patients was double that of poor PS patients, at 15.4 months versus 7.6 months. RRs were $36 \%$ and $22 \%$, respectively. Importantly, this regimen was well tolerated even among poor PS patients. A slightly different regimen, consisting of treatment on a 28-day cycle with gemcitabine at $1,000 \mathrm{mg} / \mathrm{m}^{2}$ on days 1,8 , and 15 and oxaliplatin at $100 \mathrm{mg} / \mathrm{m}^{2}$ on days 1 and 15 , yielded a $26 \% \mathrm{RR}$ and 11-month median OS time and was similarly well tolerated [79]. Finally, in a reported Italian study including nine GBC patients and $15 \mathrm{CC}$ patients, a 50\% RR and 14-month median OS time were reported [80]. Myelosuppression and grade 1-2 peripheral neuropathy were the most significant toxicities reported among all three trials.
Gemcitabine has also been evaluated in combination with fluorouracil [70, 81]. Gemcitabine in combination with capecitabine was initially evaluated in two single-arm phase II trials. Both trials were fairly large, 44 and 45 patients, respectively, with approximately half of the patients with $\mathrm{GBC}$, and the vast majority with metastatic disease $[82,83]$. This regimen was well tolerated, with neutropenia and thrombocytopenia as the most significant toxicities. The two trials demonstrated remarkably similar resultsthe median OS times in both were 14 months, and RRs of $31 \%$ and $32 \%$ were reported. A larger subsequent trial of the same regimen was similarly effective, with an RR of $29 \%$ and a median OS time of 12.7 months [84].

\section{Randomized Phase III Studies}

An earlier phase III trial in BTC patients compared etoposide, 5-FU, and leucovorin (FELV) with epirubicin, cisplatin, and 5-FU (ECF) [85]. As a result of poor recruitment (54 of the planned 119 patients), the trial was underpowered to detect a significant difference in terms of OS. The objective RRs were similar for the two arms: ECF, $19.2 \%(95 \%$ CI, 6.55\%-39.3\%); FELV, 15\% (95\% CI, 3.2\%-37.9\%). 
Table 4. Randomized phase III study comparing gemcitabine plus cisplatin with gemcitabine alone in advanced biliary tract cancers

\begin{tabular}{lllll}
\hline Endpoint & $\begin{array}{l}\text { Gemcitabine + cisplatin } \\
(\boldsymbol{n}=\mathbf{2 0 4})\end{array}$ & $\begin{array}{l}\text { Gemcitabine } \\
(\boldsymbol{n}=\mathbf{2 0 6})\end{array}$ & $\begin{array}{l}\text { Hazard ratio } \\
(\mathbf{9 5 \%} \text { CI })\end{array}$ & \begin{tabular}{l}
$\boldsymbol{p}$-value \\
\hline OS (mos)
\end{tabular} \\
PFS (mos) & 11.7 & 8.3 & $0.70(0.54-0.89)$ & .002 \\
Response rate (\%) & 8.4 & 6.5 & $0.72(0.57-0.90)$ & .003 \\
Disease control rate (\%) (CR + PR + SD) & 79.1 & 16 & .256 \\
\hline Abbra & 71.2 & .256 \\
\hline
\end{tabular}

Abbreviations: CI, confidence interval; CR, complete response; OS, overall survival; PFS, progression free survival; PR, partial response; $\mathrm{SD}$, stable disease.

During the 45th annual American Society of Clinical Oncology meeting, results from a randomized phase III study comparing gemcitabine plus cisplatin with gemcitabine alone in patients with advanced or metastatic BTCs were presented [1]. That phase III study, conducted in 410 patients, including 149 patients with GBC, demonstrated that the addition of cisplatin to gemcitabine afforded significant progression-free survival (PFS) (median, 8.4 months versus 6.5 months; hazard ratio [HR], 0.72; 95\% CI, 0.57$0.90 ; p=.003$ ) and OS (median, 11.7 months versus 8.3 months; HR, 0.70; 95\% CI, 0.54-0.89; $p=.002$ ) benefits (Table 4). In an exploratory subgroup analysis, a survival benefit was seen for both GBC and other BTCs. The safety profiles were favorable in the gemcitabine-cisplatin arm without significant added toxicity, compared with gemcitabine alone. This is the first well-conducted phase III study in BTCs that convincingly demonstrated a survival benefit of combining cisplatin with gemcitabine, compared with single-agent gemcitabine alone. It also demonstrated the feasibility of conducting a large phase III study in an orphan disease like BTC. These data may help to establish combination therapy with gemcitabine and a platinum as a new standard of systemic treatment for patients with advanced BTCs.

\section{Molecular Features and TARgeted THERAPIES IN GBC}

The epidemiologic, histological, and molecular pathogenesis of GBC has been reviewed [86]. Characteristic molecular features include mutation of KRAS, INK4a, and $p 53$ as well as human epidermal growth factor receptor (HER)-2/ Neu amplification [87-90]. Rare mutations in PI3K are described as well as a relatively high rate of $B R A F$ hotspot mutations (33\%) that are mutually exclusive of KRAS mutation [91, 92].

Activating epidermal growth factor receptor (EGFR) mutations have also been identified in a subset (13.6\%$15 \%$ ) of BTC cases, including one case of GBC [93, 94], as have EGFR amplifications [88]. Telomere length, which is associated with cellular proliferation, genomic instability, and cancer precursors in a number of other tumor sites, exhibited progressive shortening through the stages of metaplasia, dysplasia, and carcinoma in the biliary tract [95]. Transcriptional analysis of GBCs has been accomplished using serial analysis of gene expression profiling. This identified connective tissue growth factor as a prognostic marker as well as a number of other transcripts differentially expressed between GBC and normal gallbladder epithelium [96].

Single-agent erlotinib demonstrated a 17\% 6-month PFS rate, and three patients had PRs as determined by the Response Evaluation Criteria in Solid Tumors in a phase II study of 42 patients with advanced BTCs [97]. In that study, $E G F R$ mutation was not tested, and therefore it is unknown if the response correlates with $E G F R$ mutation status in BTC. Taken together, the clinical experience with erlotinib and the molecular studies suggesting a mutation rate on the order of $\sim 13 \%-15 \%$ beg the question about a highly susceptible EGFR mutant population of patients who would benefit from inhibitors along the lines of non-small cell lung cancer patients [98]. EGFR gene amplification as well as case reports of the efficacy of cetuximab in combination with either gemcitabine or gemcitabine and oxaliplatin have also been published, further prompting investigation of EGFR inhibitors in BTC [88, 99, 100]. Malka and colleagues reported their experience with a randomized phase II study comparing gemcitabine plus oxaliplatin alone with the same chemotherapy regimen in combination with cetuximab and demonstrated a higher 4-month PFS rate with the addition of cetuximab (44\% versus $61 \%$, respectively) [101]. Lapatinib, a dual EGFR-1 and HER-2/Neu inhibitor was tested in a phase II trial including both BTC and hepatocellular carcinoma patients [102]. In 17 evaluable patients with BTC, no responses were observed.

The expression of vascular endothelial growth factor (VEGF), a key mediator in tumor angiogenesis, has been 
detected in BTC, with higher VEGF expression correlated with advanced stage of disease and poor prognosis [103]. Bevacizumab, a humanized monoclonal antibody against VEGF, was tested in combination with gemcitabine and oxaliplatin in BTC patients, including a significant number of GBC patients, in a multicenter phase II trial [104]. Of the 35 patients enrolled, $40 \%$ of patients had a PR, the median overall OS time was 12.7 months (95\% CI, 7.3-18.1 months), and the median PFS time was 7.0 months (95\% CI, 5.3-10.3 months). Sorafenib, which most efficaciously targets VEGF receptor (VEGFR)-2, VEGFR-3, and platelet-derived growth factor receptor and less potently targets B-RAF and C-RAF kinases, was tested as a single agent in a phase II trial involving 31 evaluable patents [105]. Grade 3 or 4 toxicities were significant, affecting about two thirds of the patients, and two patients (6\%) had an unconfirmed PR and nine patients (29\%) had stable disease. Although these reports are promising, more definitive randomized studies are required to define the role of antiangiogenic agents in advanced BTC. The limited RR with single-agent sorafenib should not dissuade further evaluation of more potent RAF kinase inhibitors in GBC patients, particularly among those harboring $K R A S$ and $B R A F$ mutations.

\section{Conclusions}

Despite the efforts by many investigators, GBC continues to represent a major challenge in oncology. Surgical resection remains the only curative treatment for this disease.
The roles of radiation, chemoradiation, and chemotherapy in the neoadjuvant and adjuvant settings remain to be defined in prospective studies. Chemotherapy has been used extensively in advanced GBC and we have gained some experience with gemcitabine-based combination (with cisplatin and oxaliplatin or with capecitabine) regimens. The recent phase III study showing longer survival with gemcitabine and cisplatin than with gemcitabine alone has set a new standard for this disease. Molecularly targeted agents that inhibit angiogenesis and EGFR pathways are entering clinical trials. Further understanding of the molecular mechanism of carcinogenesis coupled with more extensive genetic profiling of GBC patients will help to assess the therapeutic relevance of targeting a specific pathway. Given the relatively small number of GBC cases, integration and coordination of national and international clinical research efforts remain critical to continued progress in this field and better outcomes for our patients.

\section{Author Contributions}

Conception/Design: Andrew X. Zhu, Theodore S. Hong, Aram F. Hezel, David A. Kooby

Provision of study material or patients: Andrew X. Zhu, Theodore S. Hong, Aram F. Hezel, David A. Kooby

Collection and/or assembly of data: Andrew X. Zhu, Theodore S. Hong, Aram F. Hezel, David A. Kooby

Data analysis and interpretation: Andrew X. Zhu, Theodore S. Hong, Aram F. Hezel, David A. Kooby

Manuscript writing: Andrew X. Zhu, Theodore S. Hong, Aram F. Hezel, David A. Kooby

Final approval of manuscript: Andrew X. Zhu, Theodore S. Hong, Aram F. Hezel, David A. Kooby

\section{REFERENCES}

1 Valle JW, Wasan HS, Palmer DD et al. Gemcitabine with or without cisplatin in patients (pts) with advanced or metastatic biliary tract cancer $(\mathrm{ABC})$ : Results of a multicenter, randomized phase III trial (the UK ABC-02 trial). J Clin Oncol 2009;27(15 suppl):4503.

2 Kiran RP, Pokala N, Dudrick SJ. Incidence pattern and survival for gallbladder cancer over three decades — an analysis of 10301 patients. Ann Surg Oncol 2007;14:827-832.

3 Shih SP, Schulick RD, Cameron JL et al. Gallbladder cancer: The role of laparoscopy and radical resection. Ann Surg 2007;245:893-901.

4 Yokomizo H, Yamane T, Hirata T et al. Surgical treatment of pT2 gallbladder carcinoma: A reevaluation of the therapeutic effect of hepatectomy and extrahepatic bile duct resection based on the long-term outcome. Ann Surg Oncol 2007;14:1366-1373.

5 Jarnagin WR, Gonen M, Fong Y et al. Improvement in perioperative outcome after hepatic resection: Analysis of 1,803 consecutive cases over the past decade. Ann Surg 2002;236:397-406; discussion 406-407.

6 Dixon E, Vollmer CM Jr, Sahajpal A et al. An aggressive surgical approach leads to improved survival in patients with gallbladder cancer: A 12-year study at a North American Center. Ann Surg 2005;241:385-394.

7 American Joint Committee on Cancer. AJCC Cancer Staging Manual, Seventh Edition. Chicago, IL: Springer, 2010:211-217.
8 Shirai Y, Yoshida K, Tsukada K et al. Radical surgery for gallbladder carcinoma. Long-term results. Ann Surg 1992;216:565-568.

9 Fong Y, Wagman L, Gonen M et al. Evidence-based gallbladder cancer staging: Changing cancer staging by analysis of data from the National Cancer Database. Ann Surg 2006;243:767-771; discussion 771-774.

10 Sun CD, Zhang BY, Wu LQ et al. Laparoscopic cholecystectomy for treatment of unexpected early-stage gallbladder cancer. J Surg Oncol 2005;91: 253-257.

11 Misra S, Chaturvedi A, Misra NC et al. Carcinoma of the gallbladder. Lancet Oncol 2003;4:167-176.

12 Sikora SS, Singh RK. Surgical strategies in patients with gallbladder cancer: Nihilism to optimism. J Surg Oncol 2006;93:670-681.

13 Wagholikar GD, Behari A, Krishnani N et al. Early gallbladder cancer. J Am Coll Surg 2002;194:137-141.

14 Pawlik TM, Gleisner AL, Vigano L et al. Incidence of finding residual disease for incidental gallbladder carcinoma: Implications for re-resection. J Gastrointest Surg 2007;11:1478-1486; discussion 1486-1487.

15 Benson AB 3rd, Abrams TA, Ben-Josef E et al. NCCN clinical practice guidelines in oncology: Hepatobiliary cancers. J Natl Compr Canc Netw 2009;7:350-391.

16 Shirai Y, Yoshida K, Tsukada K et al. Inapparent carcinoma of the gallbladder. An appraisal of a radical second operation after simple cholecystectomy. Ann Surg 1992;215:326-331. 
17 Chijiiwa K, Nakano K, Ueda J et al. Surgical treatment of patients with T2 gallbladder carcinoma invading the subserosal layer. J Am Coll Surg 2001;192:600-607.

18 Foster JM, Hoshi H, Gibbs JF et al. Gallbladder cancer: Defining the indications for primary radical resection and radical re-resection. Ann Surg Oncol 2007; 14:833-840.

19 Suzuki S, Yokoi Y, Kurachi K et al. Appraisal of surgical treatment for pT2 gallbladder carcinomas. World J Surg 2004;28:160-165.

20 Wakai T, Shirai Y, Hatakeyama K. Radical second resection provides survival benefit for patients with T2 gallbladder carcinoma first discovered after laparoscopic cholecystectomy. World J Surg 2002;26:867-871.

21 Wise PE, Shi YY, Washington MK et al. Radical resection improves survival for patients with pT2 gallbladder carcinoma. Am Surg 2001;67: 1041-1047.

22 Miyazaki M, Itoh H, Ambiru S et al. Radical surgery for advanced gallbladder carcinoma. Br J Surg 1996;83:478-481.

23 Cubertafond P, Gainant A, Cucchiaro G. Surgical treatment of 724 carcinomas of the gallbladder. Results of the French Surgical Association Survey. Ann Surg 1994;219:275-280.

24 Onoyama H, Yamamoto M, Tseng A et al. Extended cholecystectomy for carcinoma of the gallbladder. World J Surg 1995;19:758-763.

25 Balachandran P, Agarwal S, Krishnani N et al. Predictors of long-term survival in patients with gallbladder cancer. J Gastrointest Surg 2006;10: $848-854$.

26 Donohue JH, Nagorney DM, Grant CS et al. Carcinoma of the gallbladder. Does radical resection improve outcome? Arch Surg 1990;125:237-241.

27 Fong Y, Jarnagin W, Blumgart LH. Gallbladder cancer: Comparison of patients presenting initially for definitive operation with those presenting after prior noncurative intervention. Ann Surg 2000;232:557-569.

28 Weber SM, DeMatteo RP, Fong Y et al. Staging laparoscopy in patients with extrahepatic biliary carcinoma. Analysis of 100 patients. Ann Surg 2002;235:392-399.

29 Schirmer B. Using resources wisely: Determining the indication for staging laparoscopy. Ann Surg 2002;235:8-9.

30 Goere D, Wagholikar GD, Pessaux P et al. Utility of staging laparoscopy in subsets of biliary cancers: Laparoscopy is a powerful diagnostic tool in patients with intrahepatic and gallbladder carcinoma. Surg Endosc 2006; 20:721-725.

31 Endo I, Shimada H, Tanabe M et al. Prognostic significance of the number of positive lymph nodes in gallbladder cancer. J Gastrointest Surg 2006; 10:999-1007.

32 Frena A, La Guardia G, Martin F. Outcome of radical surgery for carcinoma of the gallbladder according to the tumor node metastasis and Japanese Society of Biliary Surgery stages. J Gastrointest Surg 2004;8:580590.

33 Kai M, Chijiiwa K, Ohuchida J et al. A curative resection improves the postoperative survival rate even in patients with advanced gallbladder carcinoma. J Gastrointest Surg 2007;11:1025-1032.

34 Nakata T, Kobayashi A, Miwa S et al. Impact of tumor spread to the cystic duct on the prognosis of patients with gallbladder carcinoma. World J Surg 2007;31:155-161; discussion 162-163.

35 Giuliante F, Ardito F, Vellone M et al. Port-sites excision for gallbladder cancer incidentally found after laparoscopic cholecystectomy. Am J Surg 2006;191:114-116.

36 Steinert R, Nestler G, Sagynaliev E et al. Laparoscopic cholecystectomy and gallbladder cancer. J Surg Oncol 2006;93:682-689.

37 Matsumoto Y, Fujii H, Aoyama H et al. Surgical treatment of primary car- cinoma of the gallbladder based on the histologic analysis of 48 surgical specimens. Am J Surg 1992;163:239-245.

38 Jarnagin WR, Ruo L, Little SA et al. Patterns of initial disease recurrence after resection of gallbladder carcinoma and hilar cholangiocarcinoma: Implications for adjuvant therapeutic strategies. Cancer 2003;98:16891700.

39 Houry S, Schlienger M, Huguier M et al. Gallbladder carcinoma: Role of radiation therapy. Br J Surg 1989;76:448-450.

40 Mahe M, Stampfli C, Romestaing P et al. Primary carcinoma of the gallbladder: Potential for external radiation therapy. Radiother Oncol 1994; 33:204-208.

41 Kraybill WG, Lee H, Picus J et al. Multidisciplinary treatment of biliary tract cancers. J Surg Oncol 1994;55:239-245.

42 Lindell G, Holmin T, Ewers SB et al. Extended operation with or without intraoperative (IORT) and external (EBRT) radiotherapy for gallbladder carcinoma. Hepatogastroenterology 2003;50:310-314.

43 Mojica P, Smith D, Ellenhorn J. Adjuvant radiation therapy is associated with improved survival for gallbladder carcinoma with regional metastatic disease. J Surg Oncol 2007;96:8-13.

44 Todoroki $\mathrm{T}$, Kawamoto $\mathrm{T}$, Otsuka $\mathrm{M}$ et al. Benefits of combining radiotherapy with aggressive resection for stage IV gallbladder cancer. Hepatogastroenterology 1999;46:1585-1591.

45 Itoh H, Nishijima K, Kurosaka Y et al. Magnitude of combination therapy of radical resection and external beam radiotherapy for patients with carcinomas of the extrahepatic bile duct and gallbladder. Dig Dis Sci 2005; 50:2231-2242.

46 Kresl JJ, Schild SE, Henning GT et al. Adjuvant external beam radiation therapy with concurrent chemotherapy in the management of gallbladder carcinoma. Int J Radiat Oncol Biol Phys 2002;52:167-175.

47 Czito BG, Hurwitz HI, Clough RW et al. Adjuvant external-beam radiotherapy with concurrent chemotherapy after resection of primary gallbladder carcinoma: A 23-year experience. Int J Radiat Oncol Biol Phys 2005; 62:1030-1034.

48 Fuller CD, Thomas CR Jr, Wong A et al. Image-guided intensity-modulated radiation therapy for gallbladder carcinoma. Radiother Oncol 2006; $81: 65-72$.

49 Hezel AF, Zhu AX. Systemic therapy for biliary tract cancers. The Oncologist 2008;13:415-423.

50 Eckel F, Schmid RM. Chemotherapy in advanced biliary tract carcinoma: A pooled analysis of clinical trials. Br J Cancer 2007;96:896-902.

51 Yonemoto N, Furuse J, Okusaka T et al. A multi-center retrospective analysis of survival benefits of chemotherapy for unresectable biliary tract cancer. Jpn J Clin Oncol 2007;37:843-851.

52 Gallardo J, Rubio B, Villanueva L et al. Gallbladder cancer, a different disease that needs individual trials. J Clin Oncol 2005;23:7753-7754; author reply $7754-7755$.

53 Gallardo JO, Rubio B, Fodor M et al. A phase II study of gemcitabine in gallbladder carcinoma. Ann Oncol 2001;12:1403-1406.

54 Reyes-Vidal J, Gallardo J, Yáñez E et al. Gemcitabine: Gemcitabine and cisplatin in the treatment of patients with unresectable or metastatic gallbladder cancer: Results of the phase II GOCCHI study 2000-13 [abstract 1095]. Proc Am Soc Clin Oncol 2003;22:273.

55 Doval DC, Sekhon JS, Gupta SK et al. A phase II study of gemcitabine and cisplatin in chemotherapy-naive, unresectable gall bladder cancer. $\mathrm{Br} \mathrm{J}$ Cancer 2004;90:1516-1520.

56 Choi CW, Choi IK, Seo JH et al. Effects of 5-fluorouracil and leucovorin 
in the treatment of pancreatic-biliary tract adenocarcinomas. Am J Clin Oncol 2000;23:425-428.

57 Ducreux M, Rougier P, Fandi A et al. Effective treatment of advanced biliary tract carcinoma using 5-fluorouracil continuous infusion with cisplatin. Ann Oncol 1998;9:653-656.

58 Ellis PA, Norman A, Hill A et al. Epirubicin, cisplatin and infusional 5-fluorouracil (5-FU) (ECF) in hepatobiliary tumours. Eur J Cancer 1995; 31A:1594-1598

59 Lee MA, Woo IS, Kang JH et al. Epirubicin, cisplatin, and protracted infusion of 5-FU (ECF) in advanced intrahepatic cholangiocarcinoma. J Cancer Res Clin Oncol 2004;130:346-350.

60 Mitry E, Taieb J, Artru P et al. Combination of folinic acid, 5-fluorouracil bolus and infusion, and cisplatin (LV5FU2-P regimen) in patients with advanced gastric or gastroesophageal junction carcinoma. Ann Oncol 2004; 15:765-769.

61 Takada T, Kato H, Matsushiro T et al. Comparison of 5-fluorouracil, doxorubicin and mitomycin $\mathrm{C}$ with 5-fluorouracil alone in the treatment of pancreatic-biliary carcinomas. Oncology 1994;51:396-400.

62 Glimelius B, Hoffman K, Sjöden PO et al. Chemotherapy improves survival and quality of life in advanced pancreatic and biliary cancer. Ann Oncol 1996;7:593-600.

63 Feisthammel J, Schoppmeyer K, Mössner J et al. Irinotecan with 5-FU/FA in advanced biliary tract adenocarcinomas: A multicenter phase II trial. Am J Clin Oncol 2007;30:319-324.

64 Hong YS, Lee J, Lee SC et al. Phase II study of capecitabine and cisplatin in previously untreated advanced biliary tract cancer. Cancer Chemother Pharmacol 2007;60:321-328.

65 Kim TW, Chang HM, Kang HJ et al. Phase II study of capecitabine plus cisplatin as first-line chemotherapy in advanced biliary cancer. Ann Oncol 2003;14:1115-1120.

66 Park SH, Park YH, Lee JN et al. Phase II study of epirubicin, cisplatin, and capecitabine for advanced biliary tract adenocarcinoma. Cancer 2006; 106:361-365.

67 Burris HA 3rd, Moore MJ, Andersen J et al. Improvements in survival and clinical benefit with gemcitabine as first-line therapy for patients with advanced pancreas cancer: A randomized trial. J Clin Oncol 1997;15:24032413.

68 Oettle H, Post S, Neuhaus P et al. Adjuvant chemotherapy with gemcitabine vs observation in patients undergoing curative-intent resection of pancreatic cancer: A randomized controlled trial. JAMA 2007;297:267277

69 Raderer M, Hejna MH, Valencak JB et al. Two consecutive phase II studies of 5-fluorouracil/leucovorin/mitomycin $\mathrm{C}$ and of gemcitabine in patients with advanced biliary cancer. Oncology 1999;56:177-180.

70 Gebbia V, Giuliani F, Maiello E et al. Treatment of inoperable and/or metastatic biliary tree carcinomas with single-agent gemcitabine or in combination with levofolinic acid and infusional fluorouracil: Results of a multicenter phase II study. J Clin Oncol 2001;19:4089-4091.

71 Kubicka S, Rudolph KL, Tietze MK et al. Phase II study of systemic gemcitabine chemotherapy for advanced unresectable hepatobiliary carcinomas. Hepatogastroenterology 2001;48:783-789.

72 Penz M, Kornek GV, Raderer M et al. Phase II trial of two-weekly gemcitabine in patients with advanced biliary tract cancer. Ann Oncol 2001; 12:183-186.

73 Mezger J, Sauerbruch T, Ko Y. A phase II trial of gemcitabine in gallbladder and biliary tract carcinomas. Oncologie 1998;21:232-234.

74 Meyerhardt JA, Zhu AX, Stuart K et al. Phase-II Study of Gemcitabine and Cisplatin in Patients with Metastatic Biliary and Gallbladder Cancer. Dig Dis Sci 2008;53:564-570.

75 Thongprasert S, Napapan S, Charoentum C et al. Phase II study of gemcitabine and cisplatin as first-line chemotherapy in inoperable biliary tract carcinoma. Ann Oncol 2005;16:279-281.

76 Lee GW, Kang JH, Kim HG et al. Combination chemotherapy with gemcitabine and cisplatin as first-line treatment for immunohistochemically proven cholangiocarcinoma. Am J Clin Oncol 2006;29:127-131.

77 Kim ST, Park JO, Lee J et al. A Phase II study of gemcitabine and cisplatin in advanced biliary tract cancer. Cancer 2006;106:1339-1346.

78 André $\mathrm{T}$, Tournigand $\mathrm{C}$, Rosmorduc $\mathrm{O}$ et al. Gemcitabine combined with oxaliplatin (GEMOX) in advanced biliary tract adenocarcinoma: A GERCOR study. Ann Oncol 2004;15:1339-1343.

79 Harder J, Riecken B, Kummer O et al. Outpatient chemotherapy with gemcitabine and oxaliplatin in patients with biliary tract cancer. Br J Cancer 2006;95:848-852.

80 Gebbia N, Verderame F, Di Leo et al. A phase II study of Oxaliplatin (O) and Gemcitabine $(\mathrm{G})$ first line chemotherapy in patients with advanced biliary tract cancers. Proc Am Soc Clin Oncol 2005;23:4132.

81 Alberts SR, Al-Khatib H, Mahoney MR et al. Gemcitabine, 5-fluorouracil, and leucovorin in advanced biliary tract and gallbladder carcinoma: A North Central Cancer Treatment Group phase II trial. Cancer 2005;103: $111-118$.

82 Knox JJ, Hedley D, Oza A et al. Combining gemcitabine and capecitabine in patients with advanced biliary cancer: A phase II trial. J Clin Oncol 2005;23:2332-2338.

83 Cho JY, Paik YH, Chang YS et al. Capecitabine combined with gemcitabine (CapGem) as first-line treatment in patients with advanced/metastatic biliary tract carcinoma. Cancer 2005;104:2753-2758.

84 Riechelmann RP, Townsley CA, Chin SN et al. Expanded phase II trial of gemcitabine and capecitabine for advanced biliary cancer. Cancer 2007; 110:1307-1312.

85 Rao S, Cunningham D, Hawkins RE et al. Phase III study of 5FU, etoposide and leucovorin (FELV) compared to epirubicin, cisplatin and 5FU $(\mathrm{ECF})$ in previously untreated patients with advanced biliary cancer. Br J Cancer 2005;92:1650-1654.

86 Wistuba II, Gazdar AF. Gallbladder cancer: Lessons from a rare tumour. Nat Rev Cancer 2004;4:695-706.

87 Kawamoto T, Krishnamurthy S, Tarco E et al. HER receptor family: Novel candidate for targeted therapy for gallbladder and extrahepatic bile duct cancer. Gastrointest Cancer Res 2007;1:221-227.

88 Nakazawa K, Dobashi Y, Suzuki S et al. Amplification and overexpression of c-erbB-2, epidermal growth factor receptor, and c-met in biliary tract cancers. J Pathol 2005;206:356-365.

89 Ueki T, Hsing AW, Gao YT et al. Alterations of p16 and prognosis in biliary tract cancers from a population-based study in China. Clin Cancer Res 2004;10:1717-1725

90 Rashid A, Ueki T, Gao YT et al. K-ras mutation, p53 overexpression, and microsatellite instability in biliary tract cancers: A population-based study in China. Clin Cancer Res 2002;8:3156-3163.

91 Riener MO, Bawohl M, Clavien PA et al. Rare PIK3CA hotspot mutations in carcinomas of the biliary tract. Genes Chromosomes Cancer 2008;47: $363-367$.

92 Saetta AA, Papanastasiou P, Michalopoulos NV et al. Mutational analysis of BRAF in gallbladder carcinomas in association with K-ras and p53 mutations and microsatellite instability. Virchows Arch 2004;445:179-182.

93 Leone F, Cavalloni G, Pignochino Y et al. Somatic mutations of epidermal 
growth factor receptor in bile duct and gallbladder carcinoma. Clin Cancer Res 2006;12:1680-1685.

94 Gwak GY, Yoon JH, Shin CM et al. Detection of response-predicting mutations in the kinase domain of the epidermal growth factor receptor gene in cholangiocarcinomas. J Cancer Res Clin Oncol 2005;131:649-652.

95 Hansel DE, Meeker AK, Hicks J et al. Telomere length variation in biliary tract metaplasia, dysplasia, and carcinoma. Mod Pathol 2006;19:772-779.

96 Alvarez H, Corvalan A, Roa JC et al. Serial analysis of gene expression identifies connective tissue growth factor expression as a prognostic biomarker in gallbladder cancer. Clin Cancer Res 2008;14:2631-2638.

97 Philip PA, Mahoney MR, Allmer C et al. Phase II study of erlotinib in patients with advanced biliary cancer. J Clin Oncol 2006;24:3069-3074.

98 Lynch TJ, Bell DW, Sordella R et al. Activating mutations in the epidermal growth factor receptor underlying responsiveness of non-small-cell lung cancer to gefitinib. N Engl J Med 2004;350:2129-2139.

99 Paule B, Herelle MO, Rage E et al. Cetuximab plus gemcitabine-oxaliplatin (GEMOX) in patients with refractory advanced intrahepatic cholangiocarcinomas. Oncology 2007;72:105-110.

100 Sprinzl MF, Schimanski CC, Moehler M et al. Gemcitabine in combination with EGF-receptor antibody (cetuximab) as a treatment of cholangiocarcinoma: A case report. BMC Cancer 2006;6:190.

101 Malka D, Trarbach T, Fartoux L et al. A multicenter, randomized phase II trial of gemcitabine and oxaliplatin (GEMOX) alone or in combination with biweekly cetuximab in the first-line treatment of advanced biliary cancer: Interim analysis of the BINGO trial. J Clin Oncol 2009;27(15 suppl):4520.

102 Ramanathan RK, Belani CP, Singh DA et al. A phase II study of lapatinib in patients with advanced biliary tree and hepatocellular cancer. Cancer Chemother Pharmacol 2009;64:777-783.

103 Hida Y, Morita T, Fujita M et al. Vascular endothelial growth factor expression is an independent negative predictor in extrahepatic biliary tract carcinomas. Anticancer Res 1999;19:2257-2260.

104 Zhu AX, Meyerhardt JA, Blaszkowsky LS et al. Efficacy and safety of gemcitabine, oxaliplatin, and bevacizumab in advanced biliary-tract cancers and correlation of changes in 18-fluorodeoxyglucose PET with clinical outcome: A phase 2 study. Lancet Oncol 2010;11:48-54.

105 El-Khoueiry AB, Rankin C, Lenz HJ et al. A phase II study of sorafenib (BAY 43-9006) as single agent in patients (pts) with unresectable or metastatic gallbladder cancer or cholangiocarcinomas. Proc Am Soc Clin Oncol 2007;25:4639.

106 Iyer RV, Gibbs J, Kuvshinoff B et al. A phase II study of gemcitabine and capecitabine in advanced cholangiocarcinoma and carcinoma of the gallbladder: A single-institution prospective study. Ann Surg Oncol 2007;14: 3202-3209. 